\title{
ANALISIS KUALITAS PERAIRAN SUNGAI RAMAN DESA \\ PUJODADI TRIMURJO SEBAGAI \\ SUMBER BELAJAR BIOLOGI SMA \\ PADA MATERI EKOSISTEM
}

\author{
Agus Sutanto \\ Purwasih \\ Pendidikan Biologi FKIP Universitas Muhammadiyah Metro \\ E-mail:sutanto11@gmail.com
}

\begin{abstract}
Abstract: River is one of fresh water ecosystem which is very important in human life since it is the most practical and economical source in fulfilling domestic and industrial needs. Therefore, it should meet the quality standards. The research objectives were: 1) knowing the quality of waterway in Raman River, Pujodadi, Trimurjo, based on the physical, chemical and biological aspects; 2) turning the information intoa Biology learning source on Ecosystem subject. The data were directly observed in the river by measuring the physical factors (temperature, stream, turbidity); chemical factors ( $\mathrm{pH}$, $D O$ ); and biological factor (macro invertebrates). The results were: temperature $24-29^{\circ} \mathrm{C}$; stream 0.3 - $0.6 \mathrm{~mm} / \mathrm{s}$; turbidity 33.5-3.7 NTU; $p H$ 4.1-5.2; and DO 2.07-2.35 ml/I. Furthermore, micro vertebrates found were; a) Plecoptra; b) Tricoptra; c) Mollusca, d) Ephemeroptra; and e) Hemiptra. In each station, they were classified as insects and non-insects. The insects found were: 1) Odonata; 2) Tricoptra; 3) Ephemeroptra; 4) Plecoptra. Based on those parameters, the waterway quality was qualified as light wasted. The results can be turned into student worksheet as a Biology learning source, especially on Ecosystem subject.
\end{abstract}

Kata Kunci: Kualitas Sungai, makroinvertebrata, sumber belajar.

\section{PENDAHULUAN}

Sungai merupakan perairan yang mengalir karena kualitas airnya selalu berubah dari waktu ke waktu atau bersifat dinamis. Soetjipto, (1999:97) menyatakan "Ekosistem air tawar memiliki kepentingan yang sangat berarti dalam kehidupan manusia karena ekosistem air tawar merupakan sumber paling praktis dan murah untuk memenuhi kepentingan domestik dan industri”. Oleh karena itu sungai merupakan salah satu tipe ekosistem perairan umum yang berperan bagi kehidupan biota dan juga kebutuhan manusia untuk berbagai macam kegiatan seperti dipengaruhi oleh banyak faktor, baik oleh aktifitas alam maupun aktifitas manusia di Daerah Aliran Sungai (DAS).

Air merupakan sumber daya alam yang sangat penting bagi kehidupan manusia dan makhluk lainnya di bumi. Salah satu sumber air yang ada di permukaan bumi ini yaitu sungai, maka sungai sangatlah bermanfaat bagi kehidupan manusia dan digunakan masyarakat untuk berbagai kegiatan sehari-hari termasuk kegiatan pertanian, peternakan, perikanan, dan sebagian masyarakat ada yang mengkonsumsi air sungai. 
Masalah utama sumber daya air meliputi kualitas air yang sudah tidak mampu memenuhi kebutuhan manusia yang terus meningkat serta kualitas air yang terus menurun, khususnya untuk air minum.

Pengaruh perubahan salah satu faktor yang mempengaruhi faktor lainnya adalah masuknya berbagai limbah yang dapat dikatakan pula sebagai sampah yang mempunyai potensi mencemari perairan ke dalam lingkungan sungai tersebut. Dampak dari terjadinya hal tersebut yang paling utama merasakan adalah organisme yang berada didalam sungai tersebut . Sebagai parameter biologi, makroinvertebrata mempunyai peranan penting dalam rantai makanan di ekosistem aquatik sering dijadikan sebagai indikator kestabilan, kesuburan dan kualitas perairan (Siti, 2009:47). Sungai sebagai salah satu jenis media hidup bagi organisme perairan, sering kali menjadi tempat pembuangan sampah rumah tangga baik sampah padat maupun cair, baik sampah organik maupun sampah anorganik oleh masyarakat sekitar sungai yang dapat mencemari sungai tersebut, sehingga sungai seringkali tidak terhindar dari masalah penurunan kualitas air.

Kualitas air adalah mutu air yang memenuhi standar untuk tujuan tertentu. Syarat yang ditetapkan sebagai standar mutu air berbeda-beda tergantung tujuan penggunaan, sebagai contoh, air yang digunakan untuk irigasi memiliki standar mutu yang berbeda dengan air untuk dikonsumsi. Kualitas air dapat diketahui nilainya dengan mengukur perubah fisika (Suhu, Kuat arus dan Kekeruhan), kimia ( $\mathrm{pH}$ dan DO) dan biologi (Makroinvertebrata) (Subekti, 2009 : 37).

\begin{tabular}{rrr}
\multicolumn{2}{c}{ Sungai Raman di Desa } \\
Pujodadi Kecamatan Trimurjo
\end{tabular}
merupakan salah satu sungai yang digunakan oleh penduduk masyarakat di sekitar sebagai sumber perairan utama di daerah tersebut. Selain sebagai pengairan utama pertanian, peternakan dan perikanan Sungai Raman ini digunakan sebagai pemenuhan kebutuhan sehari-hari seperti mandi, mencuci pakaian dan peralatan dapur bahkan oleh sebagian masyarakat digunakan sebagai tempat membuang sampah rumah tangga.

Berdasarkan survei yang peneliti lakukan di masyarakat pada tanggal 14 Desember 2014 yang berada di Desa Pujodadi ini terdapat 1.563 orang dengan luas wilayah sebesar $1.987 \mathrm{~km}$. Selama dua minggu ini terdapat 12 orang yang menggunakan air sungai tersebut sebagai kebutuhan sehari-hari seperti mencuci pakaian, mencuci piring, mencuci motor, pertanian, peternakan dan lain-lain. Hal ini sangat mempengaruhi kualitas perairan sungai tersebut karena semakin banyak bertambahnya penduduk yang bermukim dan beraktivitas menggunakan air sungai diduga mengakibatkan tercemar ringannya Sungai Raman, karena masyarakat sering membuang limbah rumah tangga atau limbah domestik ke sungai tersebut. Hal inilah yang dapat merusak sungai dan mengakibatkan pencemaran pada sungai tersebut.

$$
\text { Salah satu pentingnya }
$$

melakukan penelitian ini yaitu untuk mengetahui kualitas air yang dapat dimanfaatkan oleh masyarakat sekitar 
dan sebagai sumber bahan ajar biologi yang dapat dimanfaatkan dalam pembelajaran di dalam kelas. Muhfahroyin (2010:76-79) menyatakan sumber bahan ajar merupakan tempat di mana bahan ajar dapat diperoleh. Dalam mencari sumber bahan ajar, siswa dapat dilibatkan untuk mencarinya. Misalnya, siswa ditugasi untuk mencari Koran, majalah, hasil penelitian atau yang lainnya. Hal ini sesuai dengan prinsip pembelajaran siswa aktif, dan kreatif, PAIKEM, kontekstual, dan kontruktivistik. Berbagai sumber dapat kita gunakan untuk mendapatkan materi pembelajaran dari setiap standar kompetetensi dan kompetensi dasar. Sumber-sumber bahan ajar adalah buku teks, laporan hasil penelitian, jurnal, pakar bidang studi, profesional,buku kurikulum, internet, media audiovisual, lingkungan sekitar.

Dalam proses pembelajaran sumber belajar diperlukan agar dalam proses pembelajaran tersebut lebih bermakna dan terarah sehingga dapat dicapainya tujuan pembelajaran. Salah satu sumber dan media pembelajaran yang dapat membantu dalam pembelajaran adalah Lembar Kerja Praktikum Siswa (LKPS). LKPS dapat digunakan sebagai sumber belajar yang dapat dimanfaatkan sebagai sumber belajar Biologi SMA pada pokok bahasan ekosistem. LKPS ini akan memperjelas penyajian informasi dalam pembelajaran, dapat meningkatkan motivasi siswa, mengatasi keterbatasan indra, ruang, dan waktu serta dapat memberikan pengalaman belajar kepada siswa mengenai suatu peristiwa, dan memungkinkan terjadinya interaksi langsung dengan lingkungan sekitar. Penelitian bertujuan: 1) Untuk mengetahui kualitas perairan di Sungai Raman Desa Pujodadi Kecamatan Trimurjo ditinjau dari faktor fisika, kimia dan biologi perairan; 2) Sebagai sumber belajar biologi pada materi ekosistem.

\section{METODE PENELITIAN}

Jenis penelitian ini adalah Deskriptif. Objek penelitian adalah sampel air Sungai Raman. Lokasi penelitian adalah Sungai Raman, Desa Pujodadi, Kecamatan Trimurjo. Fokus penelitian ini adalah mengenai kualitas ekosistem perairan di Sungai Raman terutama ditinjau dari faktor fisika (suhu, kuat arus dan kekeruhan), kimia ( $\mathrm{pH}$ dan DO), dan biologi (makroinvertebrata) perairan.

Teknik pengumpulan data dalam penelitian ini dilakukan dengan cara melakukan pengambilan sampel pada titik stasiun Hulu, tengah dan hilir, kemudian mengamati faktor fisika (suhu, kuat arus dan kekeruhan) kimia (pH dan DO) dan Biologi (Makroinvetebrata) di laboratorium PMIPA Universitas Muhammadiyah Metro. Analisis data dilakukan dengan cara membandingkan data fisik-kimia perairan dengan Standar Kualitas Air Bersih Menurut PerMenKes RI No. 617/MenKes/ PER/X/2002.

\section{HASIL}

Setelah dilakukan penelitian di Sungai Raman Desa Pujodadi Kecamatan Trimurjo Lampung Tengah maka didapat hasil pengukuran parameter kualitas air sebagai berikut: 


\section{Faktor Fisika}

\section{Suhu}

Dari hasil penelitian dapat diketahui suhu air pada saat pengambilan sampel yaitu dapat dilihat pada gambar berikut:

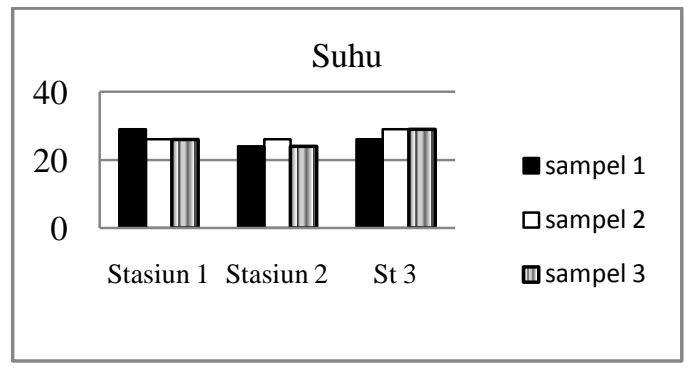

Gambar 1. Diagram Hasil Pengukuran Suhu Sungai Tiga Sampel dengan Tiga Kali Pengulangan

\section{Kuat Arus}

Hasil dari pengukuran Kuat arus yang dilakukan di Sungai Raman dapat dilihat pada gambar berikut.

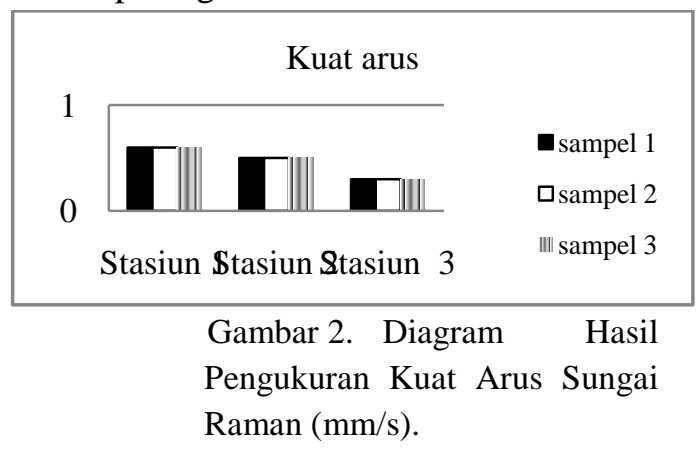

\section{Kekeruhan}

Dari hasil penelitian dapat diketahui kekeruhan di Sungai Raman yaitu dapat dilihat pada tabel dan gambar di bawah ini:

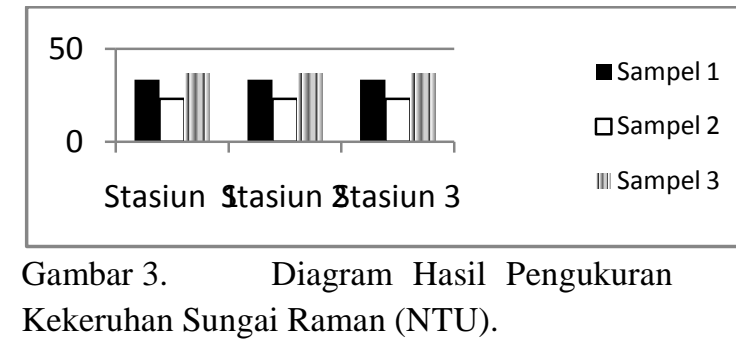

\section{Faktor Kimia}

\section{1. $\mathbf{p H}$}

Hasil pengukuran pH yang merupakan faktor kimia dapat diketahui keadaan kualitas perairan Sungai Raman Desa Pujodadi Kecamatan Trimurjo dapat dilihat pada gambar berikut ini:

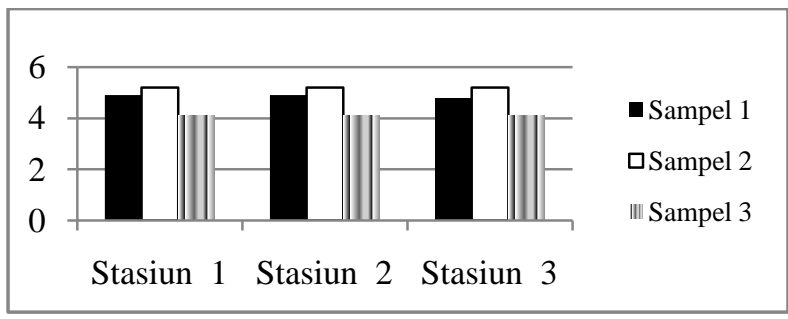

Gambar 4. Diagram Hasil Pengukuran pH Sungai Raman.

\section{Oksigen Terlarut (Dissolved Oxygen) \\ Hasil pengukuran DO di} masing-masing stasiun pada penelitian dapat dilihat pada tabel dan gambar di bawah ini:

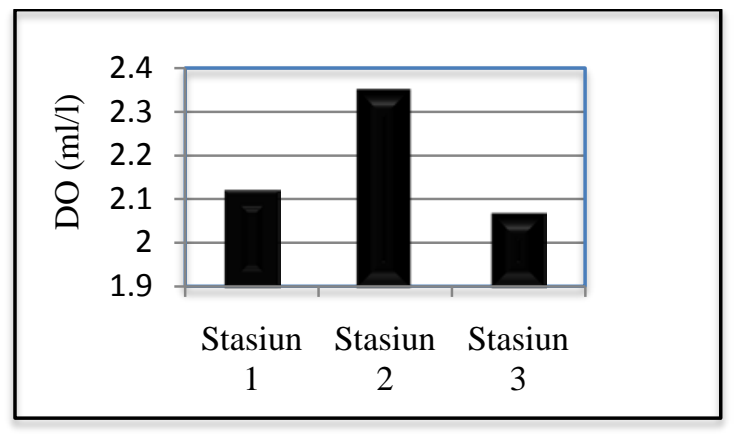

Gambar 5. Diagram Hasil Pengukuran DO (ml/l) Sungai Raman.

\section{Faktor Biologis}

Jenis-jenis makroinvertebrata pada setiap stasiun pengamatan di perairan Sungai Raman Desa Pujodadi Kecamatan Trimurjo dapat dilihat pada tabel berikut ini: 
Tabel 1. Hasil Pengambilan Sampel Makroinvertebrata

\begin{tabular}{|c|c|c|c|c|c|c|c|c|c|c|c|}
\hline \multirow{2}{*}{ No } & \multirow{2}{*}{ Famili } & \multirow{2}{*}{ Jenis } & \multicolumn{3}{|c|}{ S1 } & \multicolumn{3}{|c|}{$\mathrm{S} 2$} & \multicolumn{3}{|c|}{ S3 } \\
\hline & & & 1 & 2 & 3 & 1 & 2 & 3 & 1 & 2 & 3 \\
\hline \multirow[t]{5}{*}{1} & \multirow[t]{5}{*}{ Tricoptra } & 1. Sericosmatidae & 19 & 11 & 8 & 7 & 2 & 2 & 21 & 9 & - \\
\hline & & 2. Lepidosmatidae & 2 & 2 & 5 & 11 & - & 1 & 3 & - & - \\
\hline & & 3. Glossosomatidae & - & 1 & 4 & 1 & 1 & 1 & 3 & 3 & 3 \\
\hline & & 4. $\quad$ Hydropschydae & 7 & 2 & - & 2 & 2 & 2 & 1 & - & - \\
\hline & & 5. Psychmyidae & - & - & - & 1 & 1 & 1 & 1 & 1 & - \\
\hline 2 & Planaria & & 1 & 1 & 1 & - & - & - & - & - & - \\
\hline \multirow[t]{2}{*}{3} & \multirow[t]{2}{*}{ Plecoptra } & 1. Perlidae & 3 & 3 & 2 & - & 1 & 1 & - & - & - \\
\hline & & 2. Peleodidae & - & 7 & 1 & - & - & - & - & 1 & 1 \\
\hline \multirow[t]{4}{*}{4} & \multirow[t]{4}{*}{ Ephemeroptra } & 1. Leptophlebidae & 24 & 18 & 2 & 17 & 9 & 3 & 9 & 2 & 2 \\
\hline & & 2. Pseudocleon & 12 & 1 & 1 & 5 & 1 & - & 3 & 2 & - \\
\hline & & 3. Eldyonuridae & - & - & - & 17 & 17 & 3 & 2 & 2 & 2 \\
\hline & & 4. Caebidae & 27 & - & - & 20 & 2 & - & 19 & 1 & - \\
\hline \multirow[t]{5}{*}{5} & \multirow[t]{5}{*}{ Odonata } & 1. Gompidae & 8 & 3 & 2 & - & - & - & 2 & 2 & 2 \\
\hline & & 2. Plarycnematidae & - & - & 1 & - & - & - & - & - & - \\
\hline & & 3. Aeshnidae & 2 & 1 & 1 & - & - & 2 & 22 & 8 & 5 \\
\hline & & 4. Libellulidae & - & 2 & 6 & 2 & - & - & 3 & 2 & 2 \\
\hline & & 5. Cordulidae & - & - & 3 & - & 2 & 1 & - & - & 1 \\
\hline 6 & Coleoptra & 1. Elminthidae & - & - & - & - & - & - & 1 & - & 3 \\
\hline \multirow[t]{2}{*}{7} & \multirow[t]{2}{*}{ Mollusca } & 1. Pulmonata & 40 & - & - & 39 & 1 & 1 & 17 & - & 1 \\
\hline & & 2. Bivalvia & 37 & 18 & 19 & 20 & 7 & 21 & 12 & 2 & 30 \\
\hline 8 & Crustasea & 1. Gammaridae & 39 & 3 & 12 & 13 & 7 & 7 & 11 & 11 & 14 \\
\hline \multirow[t]{2}{*}{9} & \multirow[t]{2}{*}{ Hirudinae } & 1. Glossiphonidae & 8 & 8 & 4 & 3 & 3 & 3 & - & - & - \\
\hline & & 2. Hirudidae & 2 & 8 & 2 & - & 2 & 2 & - & - & - \\
\hline 10 & Oligochaeta & 1. Ubifilidae & 7 & 2 & 1 & 3 & 3 & 3 & 5 & - & - \\
\hline 11 & \multicolumn{2}{|r|}{$\mathrm{DO}$} & \multicolumn{3}{|c|}{2,12} & \multicolumn{3}{|c|}{2,35} & \multicolumn{3}{|c|}{2,07} \\
\hline 12 & \multicolumn{2}{|r|}{$\mathrm{pH}$} & \multicolumn{3}{|c|}{4,1} & \multicolumn{3}{|c|}{4,8} & \multicolumn{3}{|c|}{5,2} \\
\hline
\end{tabular}

\section{PEMBAHASAN}

Berdasarkan hasil penelitian tentang kualitas perairan Sungai Raman Desa Pujodadi Kecamatan Trimurjo dapat diketahui kualitas perairan sungai tersebut termasuk ke dalam kategori tercemar ringan hal ini dapat dilihat dalam standar kualitas air berdasarkan:

\section{Faktor Fisika}

\section{Suhu}

Suhu pada Sungai Raman ini berkisar antara $24-19^{\circ} \mathrm{C}$. Status kualitas air ini menunjukkan tingkat kondisi kualitas air yang menunjukkan kondisi tercemar ringan atau kondisi baik pada suatu sumber air dalam waktu tertentu dengan membandingkannya dengan baku mutu air yang ditetapkan. Kualitas air tersebut dapat ditentukan dengan menggunakan kombinasi parameter fisika (suhu, kuat arus dan kekeruhan), kimia (pH dan DO) dan biologis. "Degradasi kualitas air dapat terjadi akibat adanya perubahan parameter kualitas air. Perubahan tersebut dapat disebabkan oleh adanya aktivitas pembuangan limbah, baik limbah pabrik, pertanian maupun limbah domestik dari suatu pemukiman penduduk ke dalam badan air suatu 
perairan” (Rudiyanti, 2009:46). Suhu yang layak untuk organisme berkisar antara $20-30^{\circ} \mathrm{C}$. sehingga pada penentuan lokasi ini dapat menunjang keberadaan organisme makroinvertebrata yang mendiami sungai ini memiliki kelimpahan organism serta makhluk hidup biotic akuatik yang melimpah.

\section{Kuat Arus}

Pada penelitian ini kuat arus yang terdapat pada Sungai Raman berkisar antara 0,3-0,6 MM/S. Hal tersebut sangat mempengaruhi kepadatan makroinvertebrata di dasar perairan. Semakin dalam perairan maka semakin rendah keanekaraman makroinvertebrata yang didapat.

\section{Kekeruhan}

Kekeruhan yang terdapat pada Sungai Raman ini berkisar antara 23-37 NTU. Kekeruhan merupakan intensitas kegelapan di dalam air yang disebabkan bahan-bahan melayang. Keruhnya air sungai ini disebabkan oleh adanya partikel-partikel suspense seperti tanah liat, lumpur, pasir halus dan bahan organic terlarut serta plankton yang hidup di sungai itu. Pengaruh lain dalam keruhnya air ini yaitu penetrasi cahaya secara mencolok sehingga aktivitas fotosintesis makroinvertebrata dan alga menurun akibatnya produktivitas perairan sungai menurun. Kekeruhan yang tinggi juga dapat menyebabkan terganggunya sistem osmoregulasi seperti pernapasan dan daya lihat organism akuatik serta dapat menghambat penetrasi cahaya kedalam air.

\section{Faktor Kimia}

\section{1. $\mathbf{p H}$}

$\mathrm{pH}$ yang didapat dalam penelitian ini berkisar 4,1-5,2. Semakin rendah $\mathrm{pH}$ maka sedikit memberi pengaruh terhadap keanekaragaman organisme. Dengan kata lain semakin kecil $\mathrm{pH}$ yang didapat maka kemungkinan akan meningkatkan keanekaragaman organisme makroinvertebrata yang mendiami sungai tersebut.

\section{DO}

DO dalam penelitian ini juga sangat berpengaruh terhadap kualitas perairan sungai seperti pendapat Barus (dalam Tambun, 2011) menegaskan bahwa "Nilai oksigen terlarut di oksigen sebaiknya berkisar antara 6-8 mg/l, makin rendah nilai DO (Dissolved Oxygen) maka makin tinggi tingkat pencemaran ekosistem tersebut”. Penelitian DO (Dissolved Oxygen) pada Sungai Raman Desa Pujodadi ini yaitu berkisar antara 2,07-2,35 mg/L. Semakin tinggi tingkat DO maka dapat meningkatkan kelimpahaan makroinvertebrata, begitu pula sebaliknya semakin rendah DO maka akan menyebabkan tingginya dominasi makroinvertebrata.

\section{Faktor Biologi}

Kualitas perairan Sungai Raman ini termasuk kedalam kategori tercemar ringan ringan, dalam hal ini dapat dilihat berdasarkan standar kualitas air berdasarkan parameter biologis, serta keanekaragaman makrobiologi yang ditemukan di dalam sungai tersebut. Dari hasil penelitian dapat diketahui bahwa hasil penelitian makroinvertebrata pada setiap stasiun memiliki jumlah makroinvertebrata yang berbeda-beda. Hal ini disebabkan adanya perbedaan faktor fisika seperti (suhu, kuat arus dan kekeruhan), faktor kimia ( $\mathrm{pH}$ dan DO). Serta dapat diketahui hasil pengukuran keasaman atau $\mathrm{pH}$ pada Sungai Raman ini berkisar antara 4,1-5,2. Hal ini sangat mempengaruhi keberadaan makroinvertebrata karena semakin kecil 
pH yang didapat maka kemungkinan akan meningkatkan dominasi dari makroinvertebrata. Berdasarkan kriteria tersebut maka sungai Raman darai faktor fisika, kimia bdan biologis masuk katagori tercemar ringan.

\section{Pemanfaatan Hasil Penelitian sebagai Sumber Belajar Biologi}

Pada penelitian ini yang dapat digunakan dalam proses pembelajaran pada materi ekosistem adalah tentang bagaimana cara mengetahui kualitas perairan Sungai Raman baik dari faktor fisika (suhu, kuat arus dan kekeruhan), faktor kimia ( $\mathrm{pH}$ dan DO maupun faktor biologis (makroinvertebrata).

Biologi pada hakekatnya terdiri dari produk dan proses. Proses pembelajaran biologi yang baik tidak hanya dilakukan di dalam kelas saja dan siswa hanya menerima teori yang disampaikan oleh guru sehingga menyebabkan siswa tidak dapat mengembangkan ide-ide kreatif yang dimiliki oleh siswa, tetapi memerlukan pengamatan atau penelitian yang dapat membantu siswa lebih memahami lingkungan yang dapat mengembangkan pengetahuan siswa.

Berdasarkan hasil penelitian tentang analisis kualitas perairan Sungai Raman ditinjau dari faktor fisika (suhu, kuat arus dan kekeruhan), faktor kimia $(\mathrm{pH}$ dan DO), faktor biologis (makroinvertebrata) keadaan perairan Sungai Raman ini termasuk kedalam kategori tercemar ringan ringan. Hal ini dapat dilihat berdasarkan standar kualitas air berdasarkan parameter biologis, karena masyarakat yang berada disekitar Desa Pujodadi Kecamatan Trimurjo ini sebagian masyarakat menggunakannya sebagai kebutuhan sehari-hari seperti mencuci, mandi, pertanian dan peternakan. Dalam hal ini sangat mempengaruhi kualitas perairan sungai tersebut. Dengan adanya penelitian ini, untuk dapat mencegah supaya tidak terjadi pencemaran tersebut, masyarakat harus mengupayakan dan menjaga perairan sungai tersebut dengan baik, dan dapat digunakan sebagai sumber belajar bagi peserta didik tentang pentingnya kualitas perairan sungai tersebut karena sumber belajar adalah segala sesuatu yang dapat digunakan dan memberikan kemudahan kepada siswa dalam memperoleh informasi, pengetahuan, pengalaman dan keterampilan. Sumber belajar yang dipilih dan digunakan apabila sesuai dengan materi yang diajukan kepada siswa dapat mempermudah siswa untuk mencapai tujuan proses pembelajaran, karena penggunaan sumber belajar yang digunakan dalam belajar harus sesuai dengan materi yang sedang disampaikan.

Pengembangan materi hasil penelitian dapat diterapkan di dalam proses pengembangan konsep belajar sebagai dalam bentuk LKPS (Lembar Kerja Praktikum Siswa) yang disajikan dalam proses pembelajaran. Praktikum lapangan adalah bagian yang tidak dapat terlepas dari proses pembelajaran sains yang bertujuan dapat memberikan kesempatan siswa untuk mengeksplor pengetahuan yang telah diterima dalam penyampaian guru.

Berdasarkan uraian tersebut sumber belajar pada penelitian ini dapat digunakan sebagai bahan belajar di lapangan dan dapat pula digunakan sebagai media pembelajaran seperti LKPS (Lembar Kerja Praktikum Siswa). Pemanfaatan hasil penelitian ini sebagai sumber belajar biologi di tuntut memberikan keterampilan kepada peserta didik agar mampu berkomunikasi, bereksperimen, melakukan pengukuran 
dan menyimpulkan hasil penelitian dan pengamatan yang telah dilakukan.

\section{KESIMPULAN}

Berdasarkan hasil penelitian yang telah diungkapkan dalam hasil dan pembahasan maka dapat disimpulkan bahwa:

1. Dapat diketahui kualitas perairan di Sungai Raman Desa Pujodadi Kecamatan Trimurjo ditinjau dari

a. Faktor Fisika

1) Suhu, pada perairan Sungai Raman ini berkisar antara 24-29 ${ }^{\circ} \mathrm{C}$. Hal ini sangan mempengaruhi pada laju metabolisme organisme seperti pertumbuhan dan perkembangbiakan

2) Kuat arus, sangat mempengaruhi keberadaan makroinvertebrata karena semakin besar kuat arus sungai maka akan semakin sedikit makroinvertebrata yang ada didalamnya. Kuat arus di Sungai Raman ini mencapai 0,3-0,6 $\mathrm{MM} / \mathrm{S}$.

3) Kekeruhan, pada Sungai Raman ini mencapai 33,537 NTU sehingga dapat menyebabkan

terganggunya sistem osmoregulasi seperti pernapasan dan daya lihat organismeakuantik serta dapat menghambat penetrasi cahaya ke dalam air. b. Faktor Kimia

1. Keasaman atau pH pada Sungai Raman ini berkisar antara 4,1-5,2 H. Hal ini sangat mempengaruhi keberadaan

makroinvertebrata karena semakin kecil $\mathrm{pH}$ yang didapat maka kemungkinan akan meningkatkan dominasi dari makroinvertebrata.

2. DO pada Sungai Raman berkisar 2,07-2,35 $\mathrm{mg} / \mathrm{L}$. Hal ini dapat mempengaruhi keberadaan makroinvertebtara, karena semakin tinggi DO dapat meningkatkan kelimpahan makroinvertebrata.

c. Faktor Biologis

Kualitas perairan Sungai Raman ini termasuk kedalam kategori tercemar ringan ringan, dalam hal ini dapat dilihat berdasarkan standar kualitas air berdasarkan parameter biologis, serta keanekaragaman makrobiologi yang ditemukan di dalam sungai tersebut adalah Plecoptra, Tricoptra, Mollusca, Ephemeroptra, Hemiptra, dari famili yang ditemukan pada setiap stasiun dapat digolongkan menjadi insekta dan non insekta, famili yang termasuk kedalam jenis insekta adalah famili Odonata, Tricoptra, Ephemeroptra, Plecoptra. Sedangkan yang tidak termasuk insekta adalah famili Gastropoda, Bivalva. 
2. Sumber belajar biologi yang dapat menggunakan hasil penelitian ini adalah keanekaragaman makrobiologi yang didapat, paling tidak dapat menjelaskan materi ekosistem sungai, dengan demikian hasil penelitian keanekaragaman makrobiologi dapat memberikan wawasan dan pengaruh siswa dalam memahami konsep belajar biologi dan lingkungan. Dengan memberi wawasan siswa dapat mengembangkan dan berfikir untuk dapat membuktikan kebenaran dari teori yang telah diterima, dalam proses pembelajaran di dalam kelas.

\section{SARAN}

Perlu diadakan penelitian yang lebih mendetail mengenai keanekaragaman makrobiologi dengan berbagai metode yang berada pada Sungai Raman, Kecamatan Trimurjo, agar hasilnya pun lebih mendetail dan akurat. Hal tersebut dapat dilakukan untuk mengantisipasi pencemaran sungai yang lebih jauh lagi terkait dengan semakin banyaknya sungaisungai yang tercemar ringan. Selain itu bagi masyarakat awam pada umumnya perlu diadakannya penyuluhan serta pengawasan terhadap pengguna sungai sesuai dengan fungsinya khususnya pada Sungai Raman, Daerah Pujodadi, Kecamatan Trimurjo. Misalnya dengan upaya pembersihan sekitar wilayah Sungai Raman oleh pemerintahan yang berwewenang bersama masyarakat sekitar sebagai wujud dari program kebersihan sungai.

\section{DAFTAR PUSTAKA}

Muhfahroyin. 2010. Telaah Biologi SMA. Malang: Tunggal Mandiri.

Rudiyanti, Siti. 2009. Kualitas Perairan Sungai Banger Pekalongan Berdasarkan Indikator Biologis. Jurnal Saintek Perikanan Vol.4, No.2, Hal 46-52.

Soetjipta. 1999. Dasar-dasar Ekologi Hewan. Jakarta:
DEPDIKBUD.

Subekti. 2009. Standar Kualitas Perairan Sungai. Jurnal Teknologi Lingkungan. Vol. 2, No. 1, Hal 37.

Siti. 2009. Degradasi Kualitas Perairan Sungai. Jurnal Teknologi Proses. Vol. 8, No. 4, Hal. 46.

Tambun, Radius. 2011. Konsep Pengelolaan Kualitas Air Sungai Berdasarkan Indikator Biologis Makroinvertebrata Air. Medan: Pascasarjana UNSU. 